\title{
High Degree Atrioventricular Block in Non-ST- Segment Elevation Myocardial Infarction (NSTEMI) and Role of Early Revascularization
}

\author{
Raj Patel ${ }^{1}$, Adrian Krukowski ${ }^{2}$, Amjad Sheikh ${ }^{3}$ \\ 1. Internal Medicine, Weiss Memorial Hospital, Chicago, USA 2. Internal Medicine, Louis A Weiss Memorial Hospital, \\ Chicago, USA 3. Interventional Cardiology, Louis A Weiss Memorial Hospital, Chicago, USA
}

Corresponding author: Raj Patel, dr.rajpatel21@gmail.com

\begin{abstract}
High degree atrioventricular block (HDAVB) is a rare complication of non-ST-elevation myocardial infarction (NSTEMI) and often requires pacemaker implantation. We describe a case of reversal of HDAVB in a patient with dual atrioventricular node blood supply following coronary revascularization and potential mechanisms of such complications.
\end{abstract}

Received 06/29/2020 Review began 07/06/2020 Review ended 07/07/2020 Published 07/16/2020

() Copyright 2020 Patel et al. This is an open access article distributed under the terms of the Creative Commons Attribution License CC-BY 4.0., which permits unrestricted use, distribution, and reproduction in any medium, provided the original author and source are credited.
Categories: Cardiology, Internal Medicine, Anatomy

Keywords: nstemi, high degree av block, dual atrioventricular nodal supply, revascularization, pacemaker's implantation , cardiac conduction disorder

\section{Introduction}

As the prevalence of coronary artery disease in the general population increases, so does the incidence of non-ST-segment elevation myocardial infarction (NSTEMI) [1]. An uncommon life-threatening complication of NSTEMI is the development of a high degree AV block (HDAVB), where the atria and ventricles become almost completely dissociated. While the mechanisms of such complications are not well understood, only a few cases demonstrate the reversal of HDAVB following coronary revascularization. Here, we report a case of HDAVB reversal in NSTEMI following coronary revascularization in a patient with a co-dominant coronary artery circulation.

\section{Case Presentation}

A 47-year-old female, with a past medical history of hypothyroidism and no significant cardiac history, was admitted with complaints of atypical chest pain and generalized weakness. An initial electrocardiogram (EKG) was performed that revealed 1st-degree atrioventricular (AV) block with a ventricular rate of 42 beats per minute. Physical examination was unremarkable, and labs were significant for a Troponin-I level of 4.89 $\mathrm{ng} / \mathrm{ml}$. Emergent cardiac catheterization revealed complete occlusion of the right coronary artery (RCA) (Figure 1), and a drug-eluting stent was successfully deployed in the distal RCA (Figure 2). Minimal coronary disease of the left main and left circumflex artery was noted, and a patent AV circumflex branch originating from the left circumflex artery (LCA) was visualized (Figure 3). Two hours following initial treatment with aspirin and therapeutic enoxaparin, a repeat EKG showed conduction block progression to high degree AV block (Figure 4). However, following revascularization an additional AV nodal artery was also visualized originating from the RCA, establishing co-dominant coronary circulation. Following revascularization, the patient's conduction abnormalities gradually resolved and returned to 1:1 AV conduction (Figure 5), thus avoiding the need for cardiac pacemaker placement. 


\section{Cureus}

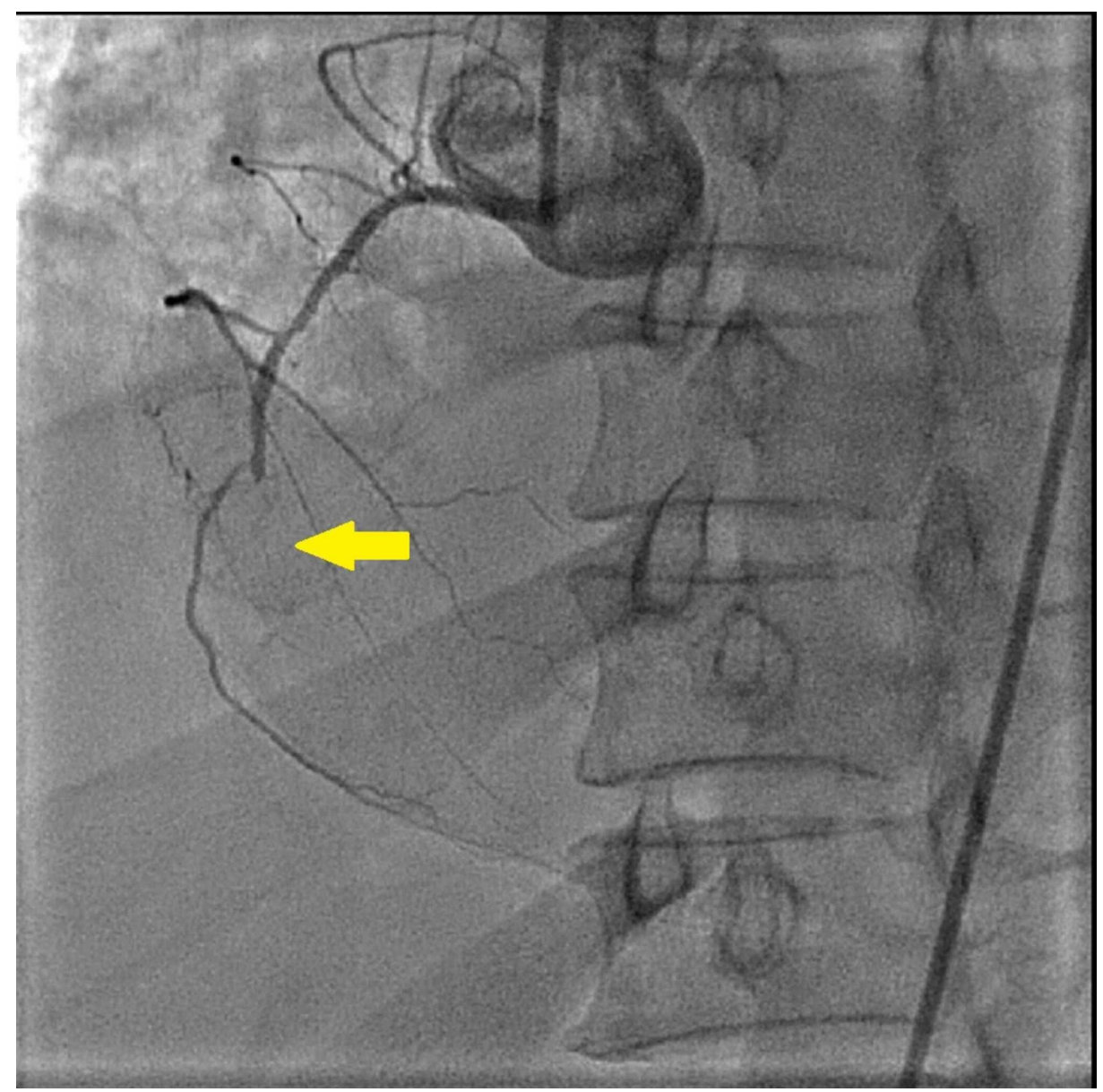

FIGURE 1: Totally occluded right coronary artery can be seen in the mid portion after giving rise to right ventricular branch 


\section{Cureus}

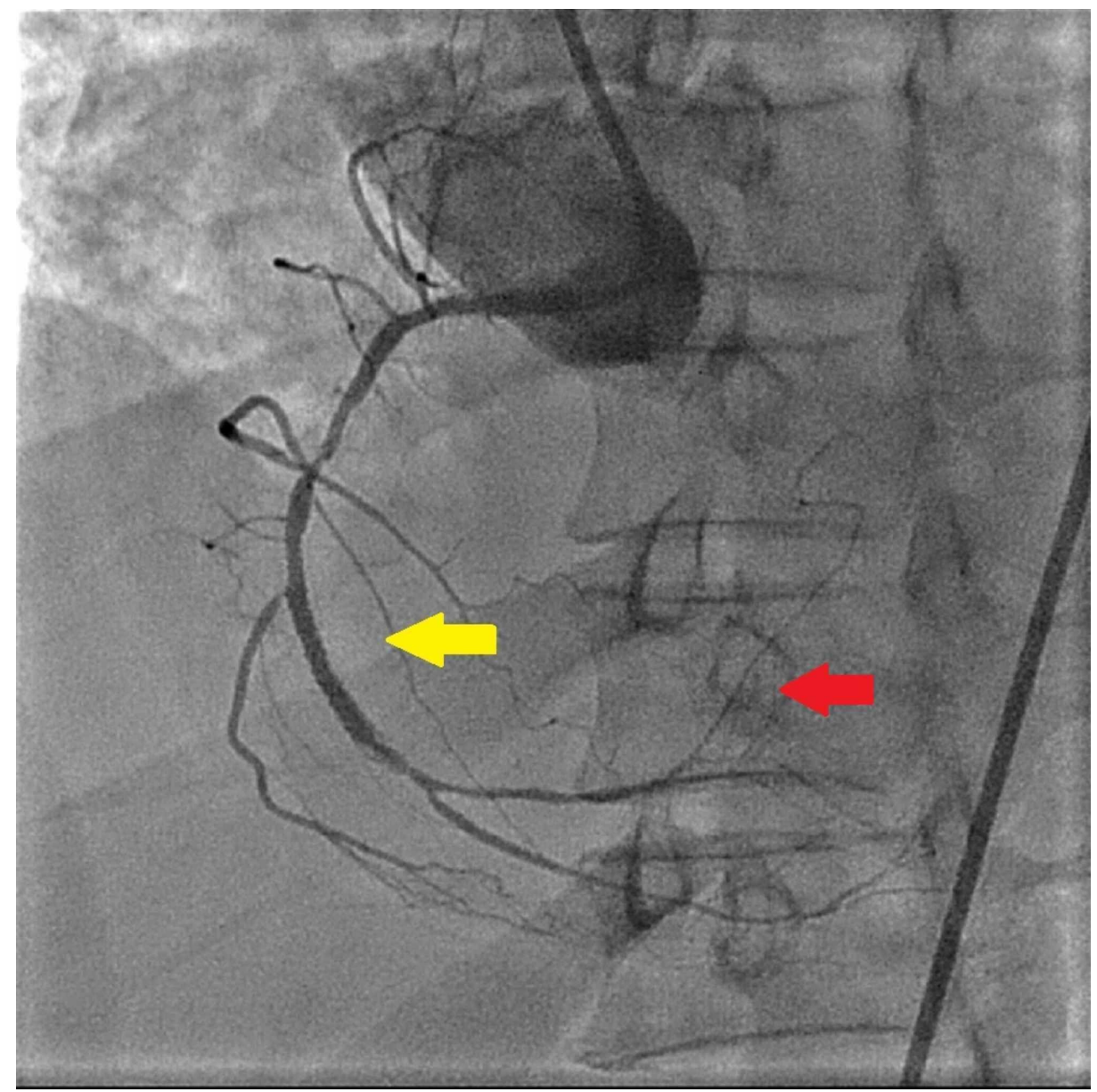

FIGURE 2: Successful drug-eluting stent placement in the right coronary artery (yellow arrow) and visualization of AV nodal artery (red arrow) 


\section{Cureus}

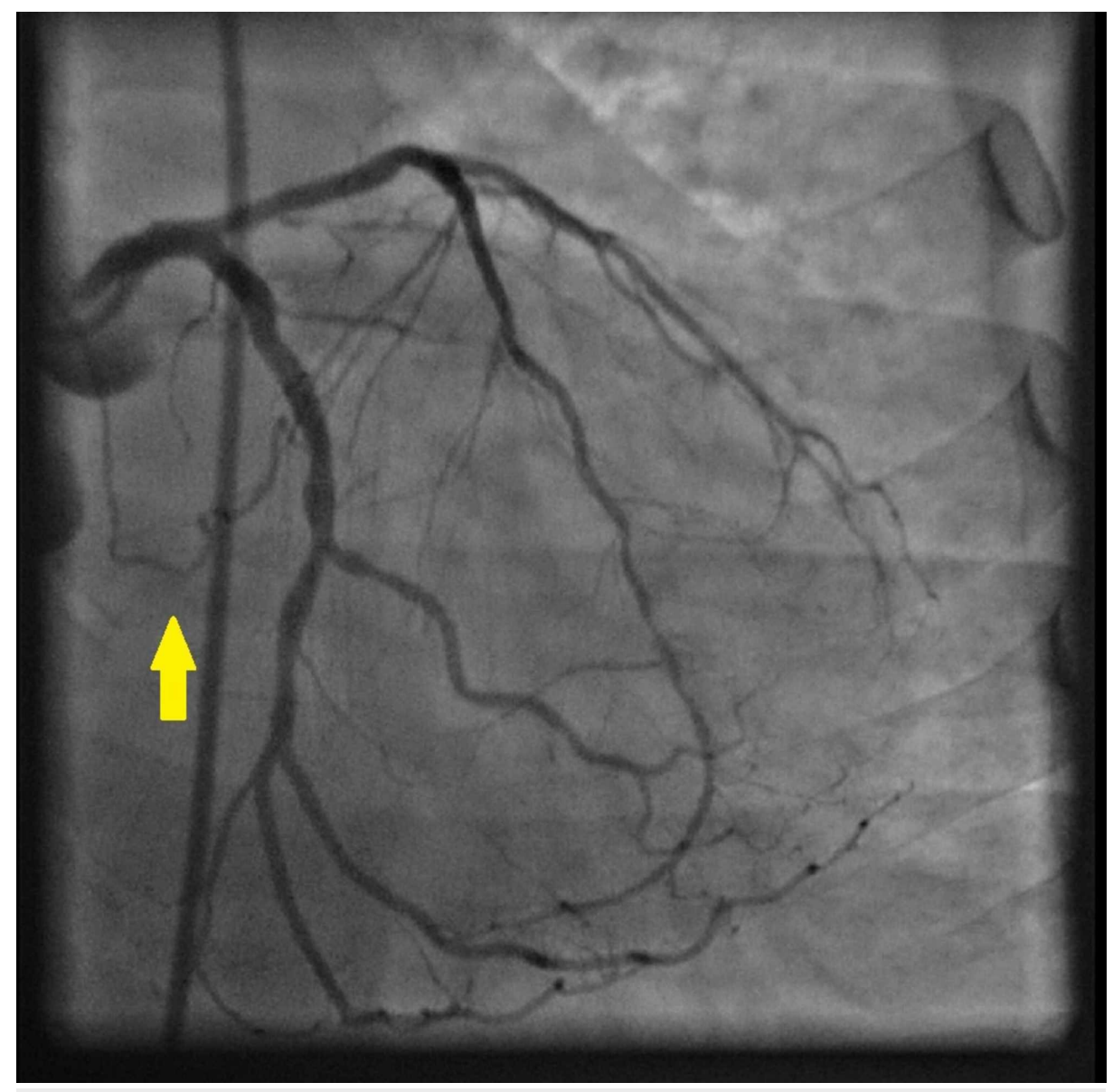

FIGURE 3: Atrioventricular circumflex artery originating from left circumflex artery

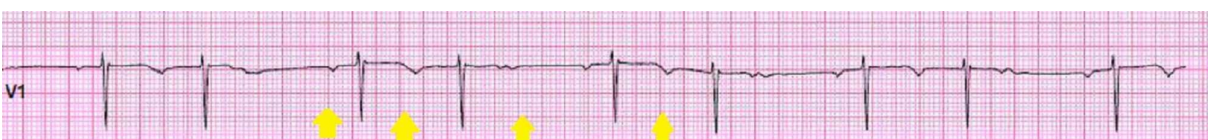

FIGURE 4: Sinus rhythm with atrioventricular dissociation and junctional bradycardia before revascularization

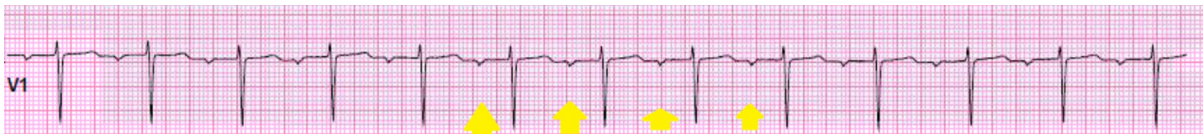

FIGURE 5: Sinus rhythm with 1st degree AV block after revascularization

\section{Discussion}

The resolution of high degree AV block following RCA revascularization has been previously described, but this is the first case of HDAVB resolution in the presence of co-dominant coronary circulation in the setting of NSTEMI [2].

HDAVB is a form of advanced second-degree heart block. It is differentiated from complete heart block by the conduction of some atrial impulses to the ventricles and absence of complete AV dissociation, whereas in former, there is no conduction of atrial impulses and there is complete AV dissociation. In an analysis of nationwide inpatient database, $0.6 \%$ of patients admitted with NSTEMI developed HDAVB, and a third of 
those patients required permanent pacemaker placement [3]. Overall, rates of post-MI conduction abnormalities are decreasing given increasing primary percutaneous coronary intervention (PCI). Most studies have reported 1 to 3 percent of patients experiencing such abnormalities [4]. However, HDAVB is associated with higher mortality because of a greater extent of myocardial and conduction system involvement. In NSTEMI, there are two possible mechanisms previously described for such complications: (1) According to vagal theory, the infarcted area causes stretch and distension of myocardium and release of chemical substances (prostaglandins, serotonin, free radicals) which activate efferent vagal fibers. This leads to hypotension and bradyarrhythmia. This phenomenon is also known as Bezold-Jarisch reflex [5]; (2) According to ischemia theory, AV conduction defects are directly related to ischemia with RCA occlusion, and such defects resolve with revascularization, as seen in our patient.

In our case, the patient presented with 1st degree AV block which quickly progressed to HDAVB and the patient required emergent percutaneous intervention. Left heart catheterization demonstrated variant coronary anatomy seen in only $2 \%$ of patients, where the AV nodal branch originates from both the RCA and LCA [6]. The return of 1:1 conduction following revascularization supports ischemia theory and ultimately averted the need for pacemaker placement and associated complications. Pacemaker placement is recommended in patients with symptomatic second- or third-degree AV block and considering pacemaker in asymptomatic patients [7]. ACC/AHA guidelines recommend management of HDAVB with ischemia-guided strategy, but there is no data available regarding whether the timing of the revascularization is associated with reversibility of such conduction abnormalities and remains to be studied [8].

\section{Conclusions}

We report first case of the patient with dual atrioventricular nodal supply presenting with NSTEMI complicated by high degree AV block. Rapid identification and early coronary revascularization of this abnormality may lead to reversal of conduction block and establishing 1:1 AV conduction thus avoiding the need for pacemaker insertion. Our case supports the ischemia-related mechanism of such complications and emphasizes the role of early intervention in order to improve outcomes.

\section{Additional Information \\ Disclosures}

Human subjects: Consent was obtained by all participants in this study. Conflicts of interest: In compliance with the ICMJE uniform disclosure form, all authors declare the following: Payment/services info: All authors have declared that no financial support was received from any organization for the submitted work. Financial relationships: All authors have declared that they have no financial relationships at present or within the previous three years with any organizations that might have an interest in the submitted work. Other relationships: All authors have declared that there are no other relationships or activities that could appear to have influenced the submitted work.

\section{References}

1. Rogers WJ, Frederick PD, Stoehr E, et al.: Trends in presenting characteristics and hospital mortality among patients with ST elevation and non-ST elevation myocardial infarction in the National Registry of Myocardial Infarction from 1990 to 2006. Am Heart J. 2008, 156:1026-1034. 10.1016/j.ahj.2008.07.030

2. Cardoso R, Alfonso CE, Coffey JO: Reversibility of high-grade atrioventricular block with revascularization in coronary artery disease without infarction: a literature review. Case Rep Cardiol. 2016, 2016:6. $10.1155 / 2016 / 1971803$

3. Misumida N, Ogunbayo GO, Kim SM, Abdel-Latif A, Ziada KM, Elayi CS: Frequency and significance of highdegree atrioventricular block and sinoatrial node dysfunction in patients with non-ST-elevation myocardial infarction. Am J Cardiol. 2018, 122:1598-1603. 10.1016/j.amjcard.2018.08.001

4. Kim HL, Kim SH, Seo JB, et al.: Influence of second- and third-degree heart block on 30-day outcome following acute myocardial infarction in the drug-eluting stent era. Am J Cardiol. 2014, 114:1658-1662. 10.1016/j.amjcard.2014.08.038

5. Chiladakis JA, Patsouras N, Manolis AS: The Bezold-Jarisch reflex in acute inferior myocardial infarction: clinical and sympathovagal spectral correlates. Clin Cardiol. 2003, 26:323-328. 10.1002/clc.4950260706

6. Sow ML, Ndoye JM, Lô EA: The artery of the atrioventricular node: an anatomic study based on 38 injectiondissections. Surg Radiol Anat. 1996, 18:183-187. 10.1007/BF02346125

7. Tracy CM, Epstein AE, DiMarco JP, et al.: 2012 ACCF/AHA/HRS focused update incorporated into the ACCF/AHA/HRS 2008 guidelines for device-based therapy of cardiac rhythm abnormalities. Circulation. 2013, 127:e283-e352. 10.1161/CIR.0b013e318276ce9b

8. Amsterdam EA, Wenger NK, Brindis RG, et al.: 2014 AHA/ACC guideline for the management of patients with non-ST-elevation acute coronary syndromes: a report of the American College of Cardiology/American Heart Association Task Force on practice guidelines. J Am Coll Cardiol. 2014, 64:139-228. 10.1016/j.jacc.2014.09.017 